ARTICLE

https://doi.org/10.1038/s41467-019-11925-z

\title{
Conductive carbon nanofiber interpenetrated graphene architecture for ultra-stable sodium ion battery
}

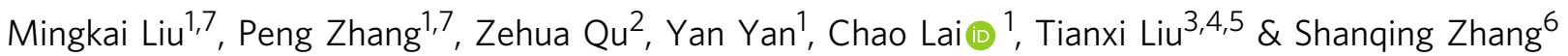

Long-term stability and high-rate capability have been the major challenges of sodium-ion batteries. Layered electroactive materials with mechanically robust, chemically stable, electrically and ironically conductive networks can effectively address these issues. Herein we have successfully directed carbon nanofibers to vertically penetrate through graphene sheets, constructing robust carbon nanofiber interpenetrated graphene architecture. Molybdenum disulfide nanoflakes are then grown in situ alongside the entire framework, yielding molybdenum disulfide@carbon nanofiber interpenetrated graphene structure. In such a design, carbon nanofibers prevent the restacking of graphene sheets and provide ample space between graphene sheets, enabling a strong structure that maintains exceptional mechanical integrity and excellent electrical conductivity. The as-prepared sodium ion battery delivers outstanding electrochemical performance and ultrahigh stability, achieving a remarkable specific capacity of $598 \mathrm{mAh} \mathrm{g}^{-1}$, long-term cycling stability up to 1000 cycles, and an excellent rate performance even at a high current density up to $10 \mathrm{~A} \mathrm{~g}^{-1}$.

\footnotetext{
${ }^{1}$ School of Chemistry \& Materials Science, Jiangsu Key Laboratory of Green Synthetic Chemistry for Functional Materials, Jiangsu Normal University, 221116 Xuzhou, P. R. China. ${ }^{2}$ State Key Laboratory of Molecular Engineering of Polymers, Department of Macromolecular Science, Fudan University, 200433 Shanghai, P. R. China. ${ }^{3}$ Key Laboratory of Synthetic and Biological Colloids, Ministry of Education, School of Chemical and Material Engineering, Jiangnan University, 214122 Wuxi, P. R. China. ${ }^{4}$ State Key Laboratory for Modification of Chemical Fibers and Polymer Materials, College of Materials Science and Engineering, Donghua University, 201620 Shanghai, P. R. China. ${ }^{5}$ Key Laboratory of Materials Processing and Mold (Zhengzhou University), Ministry of Education, 450002 Zhengzhou, P. R. China. ${ }^{6}$ Centre for Clean Environment and Energy, Griffith School of Environment, Griffith University, Gold Coast, QLD 4222, Australia. ${ }^{7}$ These authors contributed equally: Mingkai Liuand, Peng Zhang. Correspondence and requests for materials should be addressed to C.L. (email: laichao@jsnu.edu.cn) or to T.L. (email: txliu@jiangnan.edu.cn) or to S.Z. (email: s.zhang@griffith.edu.au)
} 
S odium ion batteries (SIBs), as one of the most promising candidates among next-generation energy storage systems, have attracted tremendous interest due to sodium's natural abundance and ready accessibility ${ }^{1-11}$. However, compared to lithium ions $(0.59 \AA)$, the larger diameter $(0.99 \AA)$ of sodium ions $\left(\mathrm{Na}^{+}\right)$limits the number of suitable electroactive materials and hinders the electrochemical interfacial reaction kinetics. As such, owing to the sluggish $\mathrm{Na}^{+}$insertion/extraction efficiency, the poor rate performance of SIBs has been well recognized as an inherent challenge ${ }^{12-15}$. In the last decade, much effort has been devoted to developing promising $2 \mathrm{D}$ structural anode materials, such as phosphorus ${ }^{16}$, carbonaceous materials 17,18 , metallic alloys, and two-dimensional carbides (MXenes) ${ }^{19,20}$, to improve the electrochemical performances of SIBs and promote their practical application ${ }^{21-25}$

Among the investigated electrode materials, 2D molybdenum disulfide $\left(\mathrm{MoS}_{2}\right)$, a layered transition-metal-dichalcogenide (TMD) material with S-Mo-S motifs stacked together by Van der Waals forces, is considered one of the most promising anode materials for SIBs ${ }^{26-28}$. $\mathrm{MoS}_{2}$ materials can be further modified as intercalation-type anode materials with expanded $d$-spacing to improve the electrochemical performances of state-of-art anodes. However, $\mathrm{MoS}_{2}$-based electrodes exhibit poor rate capability and fast capacity fading upon cycling due to low electrical conductivity and the huge volume variations during charge/discharge process ${ }^{29-31}$. Incorporation of $\mathrm{MoS}_{2}$ nanomaterials into highly conductive carbonaceous matrices was suggested as an effective way to address this problem ${ }^{32-35}$. To date, several $\mathrm{MoS}_{2}$-carbon hybrid materials have been developed, such as $\mathrm{MoS}_{2}$-graphene composites, $\mathrm{MoS}_{2}$-CNT hybrids, and $\mathrm{MoS}_{2}$-carbon spheres ${ }^{36-38}$. The electrochemical performance, in terms of specific capacity, has been significantly improved due to the excellent electrical conductivity offered by the carbon matrices ensuring rapid electron transfer in the charge/discharge processes. However, there is still much room for improvement in terms of rate capability and stability of these anode materials. Thus, development of $\mathrm{MoS}_{2} /$ carbon hybrids with resilient porous structure for rapid ionic transport and storage is urgently needed and of great importance.

Graphene is considered a most promising carbon material due to its inherent advantages, including large surface area, high conductivity and exceptional mechanical strength ${ }^{39-42}$. However, such advantages would vanish if the graphene sheets restack. Carbon nanotubes (CNTs) and carbon nanofibers (CNFs) are used to prevent the restacking of graphene sheets but the improvement is very limited. Such simple hybrids offer limited surface area enhancement and limited channels for ionic transfer due to the fact that the CNTs and CNFs are in parallel with the graphene plane. It is extremely challenging to steer the CNFs to vertically penetrate through the graphene plane. To the best of our knowledge, this vertical penetration has not been achieved in the literature.

In this work, inspired by the floors-and-pillars concept in construction (Supplementary Fig. 1), we design and develop a robust 3D conductive CNFs interpenetrated graphene (CNFIG) architecture by directing CNFs to penetrate through the graphene sheets. $\mathrm{MoS}_{2}$ nanoflakes are then in situ deposited on the surface of the CNFIG framework, producing a $\mathrm{MoS}_{2} @$ CNFIG hybrid. It is envisaged that the $\mathrm{MoS}_{2} @ \mathrm{CNFIG}$ hybrid possess several important advantages due to its unique structural characteristics, including: (i) excellent transportation channels can be integrally preserved during the rapid penetration of electrolyte and rapid transfer of ions for long-term cycles; greatly contributing to the high rate performance of the assembled batteries; (ii) the CNFs can simultaneously act as supporting pillars between different carbon layers and play an important role in rapid transfer of electrons; and (iii) due to their homogeneous deposition, all the active sites of $\mathrm{MoS}_{2}$ nanosheets can be thoroughly exposed to the electrolyte and $\mathrm{Na}^{+}$, which produces high energy density for the $\mathrm{MoS}_{2} @ \mathrm{CNFIG}$ hybrid. Furthermore, the $\mathrm{MoS}_{2} @ \mathrm{CNFIG}$ hybrid in this work could inspire more electrode designs with stable inner structures with high rate performance and long-term cycling stability.

\section{Results}

Structural characterizations of CNFIG architecture. The preparation of the hierarchical CNFIG architecture is schematically illustrated in Fig. 1a. CNFs with an average diameter of $1 \mu \mathrm{m}$ (Fig. 1b), were prepared from the PAA fiber membranes (Supplementary Fig. 2). The carbon fiber networks were derived from the electrospun PAA fiber networks (Supplementary Fig. 3) under chemical imidization and high-temperature carbonization. Here, the PAA matrix was polymerized by ODA and PMDA monomers (Supplementary Fig. 4). CNFs were dispersed within graphene oxide solution under strong sonication and stirring. Graphene oxide (GO) sheets with large domain size were presented in Fig. 1c. PAA powder (Supplementary Fig. 5) can be redispersed into ultrapure water with the assistance of triethylamine (TEA), forming the PAA chains. Vertically aligned channels can be clearly observed in the overall image of the carbon networks (Fig. 1d). These channels can contribute to the rapid penetration of electrolyte and quick transfer of $\mathrm{Na}^{+}$. More interestingly, numerous CNFs are perpendicularly placed across the aligned channels acting as supporting pillars between the adjacent carbon layers (Fig. 1e). Detailed morphological information can be found in the SEM image at high magnification, (Fig. 1f). Most of the CNFs are inserted through the carbon layers. This CNFIG aerogel with extremely stable channels can provide excellent transfer pathways for electrolyte and ions. Meanwhile, the supporting CNF pillars can further act as conductive bridges to accelerate the transfer of electrons, which will contribute to the electrochemical performance of the electrodes.

The vertically aligned channels, as well as the porous morphology of CNFIG, can be maintained even under large pressure. Figure $1 \mathrm{~g}$ schematically illustrates the compressible capability of the robust CNFIG aerogel due to the excellent supporting/interconnecting effect of the inserted CNFs. Figure $1 \mathrm{~h}$ presents images of CNFIG aerogel being compressed and released. The CNFIG aerogel can completely recover to its original shape without any mechanical fracture even after being compressed up to $90 \%$. The compressive stress-strain curves at the set strains $(\varepsilon)$ of $60,70,80$, and $90 \%$ for CNFIG aerogel are shown in Supplementary Fig. 6. A linear elastic region at $\varepsilon<60 \%$ and the densification region at $\varepsilon>60 \%$ can be detected in the compressive stress-strain curves. A much higher compressive stress of approximate $0.25 \mathrm{MPa}$ can be achieved at the set strain $\varepsilon=90 \%$. In addition, the cyclic stress-strain curves of CNFIG at a maximum strain of $90 \%$ were cycled more than 100 times. The stable and constant stress-strain curves in the 1st, 30th, and 100th cycles further confirm the recoverability of this CNFIG aerogel. Meanwhile, the CNFIG aerogel that was compressed 100 times shows a stable layered morphology with constant channels and supporting CNF pillars (Supplementary Fig. 7), which further confirms its robust capability ${ }^{43}$. CNFs with larger diameter of $900 \mathrm{~nm}$ can also be interpenetrated across the graphene sheets (Supplementary Fig. 8), which illustrates the general application of this fabrication strategy.

Formation mechanism of CNFIG. Figure 2 demonstrates the proposed formation mechanism of CNFIG. With prepared GO/ PAA/CNF solution vertically dipped into the liquid nitrogen, ice pillars will be homogeneously grown on a vertical direction inside 
a
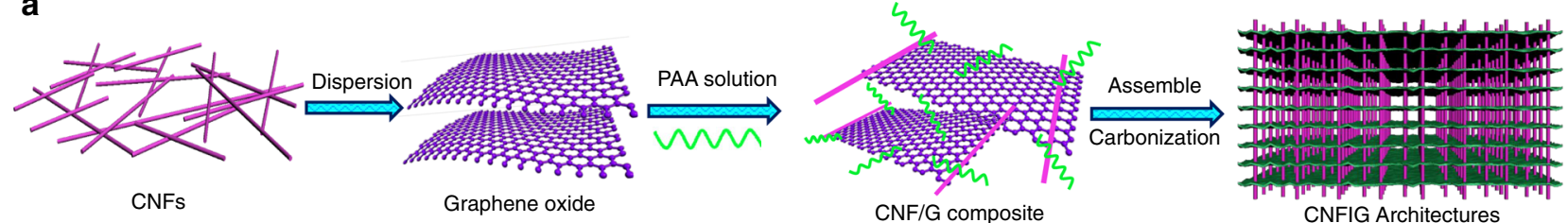

b

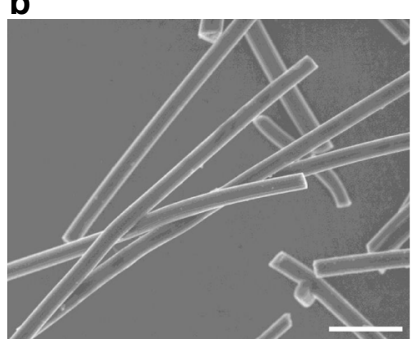

CNF/G composite

CNFIG Architectures

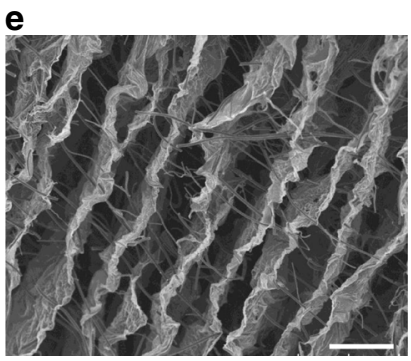

f

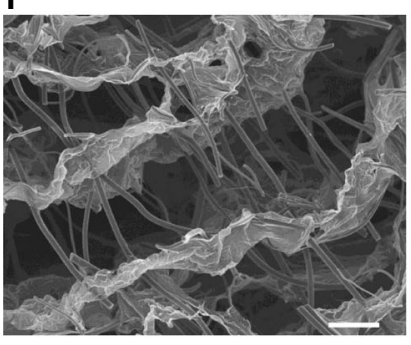

c

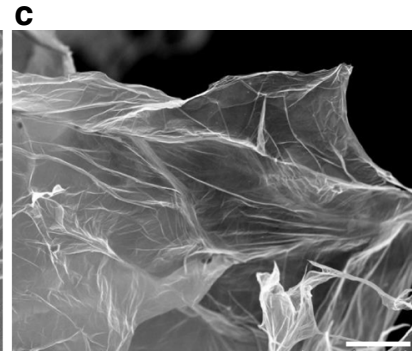

(

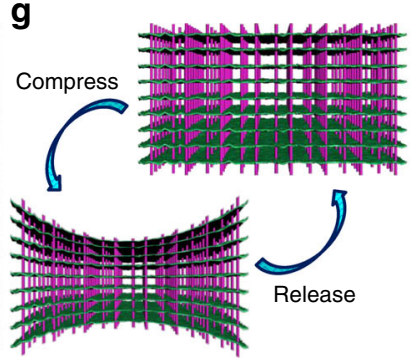

d

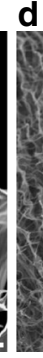

$\mathbf{h}$

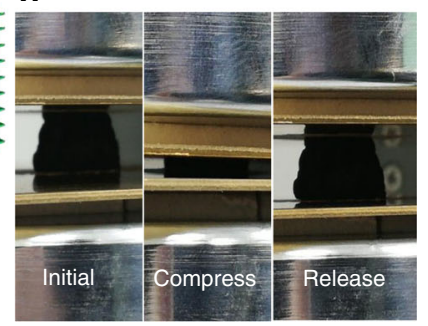

i

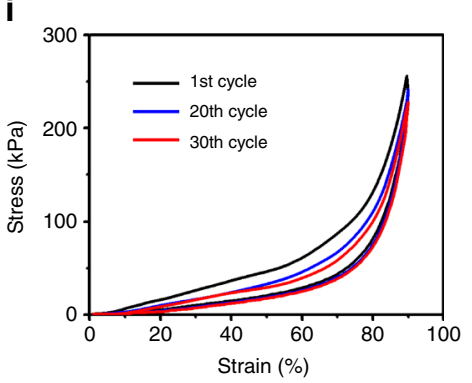

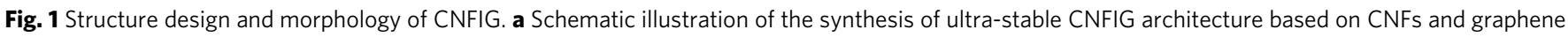
sheets; SEM images of $\mathbf{b}$ CNFs (scale bar $=5 \mu \mathrm{m}$ ) and $\mathbf{c}$ GO sheets (scale bar $=5 \mu \mathrm{m}$ ); SEM images of CNFIG architectures at $\mathbf{d}$ low (scale bar $=30 \mu \mathrm{m}$ ),

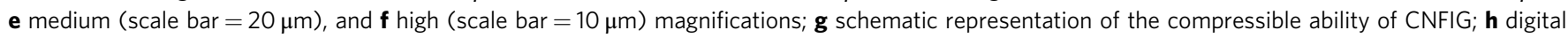
photos of the CNFIG architecture being compressed; i Stress-strain curves of CNFIG at the 1st, 20th, and 30th cycles

the formed block (Fig. 2a). Aligned pores will be created after the ice pillars were removed, resulting from the freeze-drying treatment. Here, the perpendicular alignment of CNFs might be resulted from several factors. Firstly, CNFs and GO sheets can be tightly connected with the assistance of PAA molecular chains due to the existed functional groups on their surface or on the chains of PAA (such as $-\mathrm{COOH}$, $-\mathrm{OH}$, etc.) (Fig. 2a), apart from the electrostatic interaction between CNFs and GO sheets. With ice pillars growing, PAA/GO matrix will be pushed aside to form the precursor for carbon layers. During this process, the long CNFs that attached on different GO sheets are directed to a direction vertical to the ice pillars due to the pull force $(f)$ as illustrated in Fig. 2b. Here, it should be stated that most of the CNFs can be forced to perpendicularly across the carbon layers, however, still leaving a little to be attached on the surface of the formed PAA/GO mixture layers, as seen in Fig. 2c. Secondly, the existence of PAA molecular chains and GO sheets plays an important role in the formation of CNFIG, as demonstrated in Fig. 2d-g. Disordered pores with large size will be formed if only PAA polymer matrix was used (Fig. $2 \mathrm{~d}$ ). And this phenomenon can be ascribed to the typical self-assembled aerogel of polymers as a result of the freeze treatment in liquid nitrogen ${ }^{44,45}$. However, with the assistance of introduced raw GO sheets, clearly aligned carbon layers or pores can be achieved in the obtained carbon aerogel due to the interfacial interaction of PAA chains and GO sheets (Fig. 2e) in the preparation process. The important role of PAA chains can also be demonstrated, as seen in Fig. 2f, carbonic foam with disordered porous structures will be resulted if only pristine GO and CNFs were used. This result further illustrates that the crosslink of PAA polymer chains on the surface of CNFs and GO sheets has a vital function to generate the aligned pores and carbon layers. Also, this result can be an effective confirmation of the interfacial interaction between CNFs and GO sheets. Meanwhile, if GO sheets was not used, CNF@PAA mixture that used as precursor will only create a similar self-assembled morphology as that of pure PAA matrix, as seen in Fig. 2g. Thirdly, the length of CNFs can also determine the final morphology of CNFIG. Here, the average length of the used CNFs is about $30-40 \mu \mathrm{m}$. If shorter CNFs were used (i.e. 2-3 $\mu \mathrm{m}$ ), the obtained CNFIG architecture (Fig. 2h) will only has a similar morphology as that of GO@PAA (Fig. 2e). The shorter CNFs will only be attached on the surface of carbon layers yet not perpendicularly crossed them, as demonstrated in Supplementary Fig. 9. These results demonstrate the formation mechanism of CNFIG that PAA molecular chains, GO sheets, the length of CNFs and ice pillars can play a crucial role in determining the final morphology of CNFIG architectures.

Fabrication and structural characterization of $\mathrm{MoS}_{\mathbf{2}} @ \mathrm{CNFIG}$ hybrid. The CNFIG aerogel also possesses a high electrical conductivity, up to $15.6 \mathrm{~S} \mathrm{~cm}^{-1}$, as confirmed by the electrical current-voltage curve (Supplementary Fig. 10). Meanwhile, a break copper wire can be connected by a piece of CNFIG in a turn-on electrical circle (Supplementary Fig. 11), demonstrating the good electrical conductivity of this CNFIG matrix. Here, the developed CNFIG aerogel is used as a conductive template for the homogeneous deposition of layered $\mathrm{MoS}_{2}$ nanoflakes (Fig. 3a). The robust $\mathrm{MoS}_{2} @ \mathrm{CNFIG}$ hybrid is fabricated via a versatile interfacial deposition approach and subsequent high-temperature treatment. Due to the homogeneous deposition reaction, layered $\mathrm{MoS}_{2}$ nanoflakes can be uniformly anchored on the carbon layers 


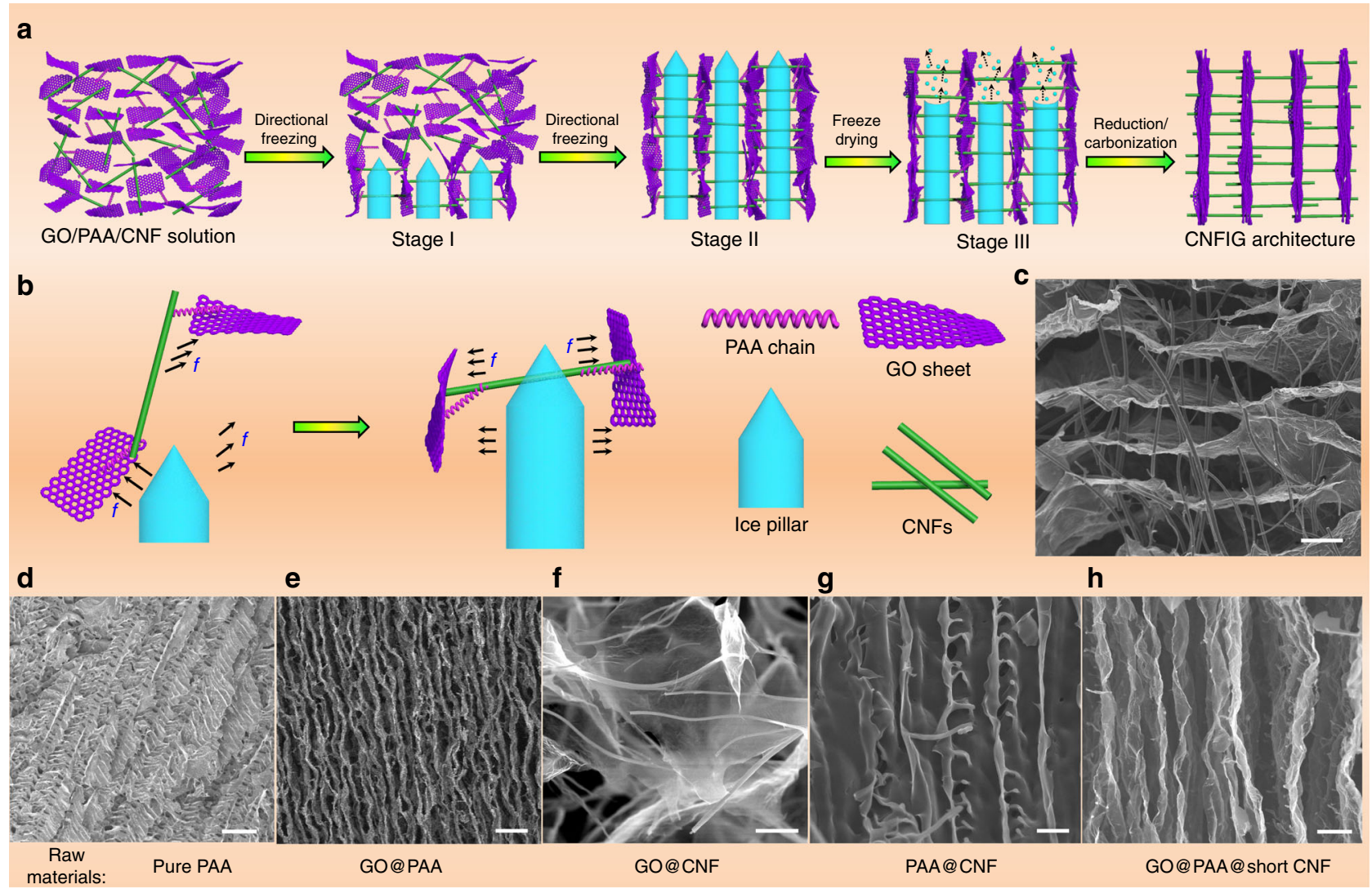

Fig. 2 The proposed formation mechanism of CNFIG: a the directional freezing leads to the creation of ice pillars, the parallel alignment of graphene sheets, and the aligned channels for CNFs. $\mathbf{b}$ the mechanism of the perpendicular alignment of the CNFs by the parallel alignment of graphene sheets. SEM images of the CNFIG: cCNFIG and carbon aerogels prepared from raw materials of $\mathbf{d}$ pure PAA matrix, e GO@PAA, fGO@CNF, $\mathbf{g}$ PAA@CNF, h GO@PAA@short CNF. (Scale bars: c $10 \mu \mathrm{m}, \mathbf{d} 30 \mu \mathrm{m}$, e $10 \mu \mathrm{m}, \mathbf{f} 4 \mu \mathrm{m}, \mathbf{g .} 5 \mu \mathrm{m}, \mathbf{h} 5 \mu \mathrm{m}$ )

a

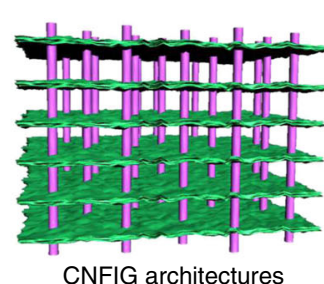

b

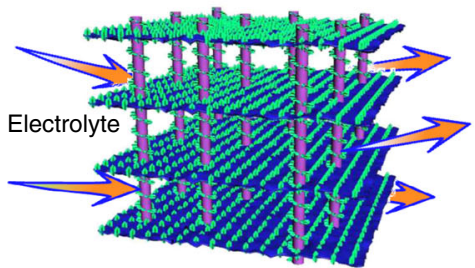

$\mathrm{MoS}_{2} @ \mathrm{CNFIG}$ architectures

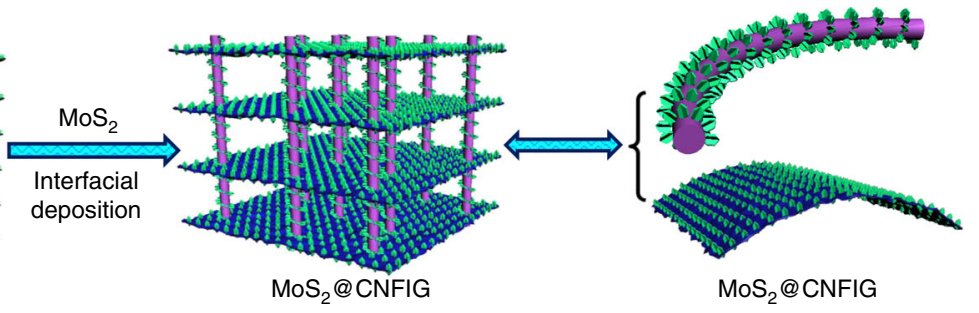

C

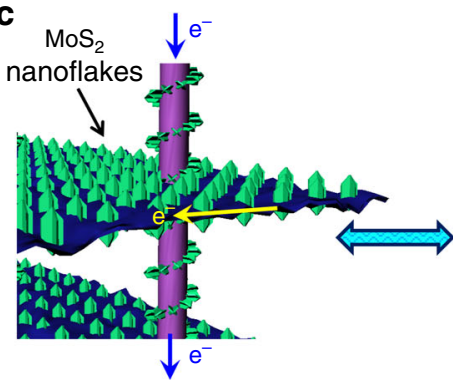

$\sum_{\mathrm{Na}^{+}}^{\mathrm{Na}^{+}} \mathrm{Na}^{+} \Downarrow_{\mathrm{Na}^{+}} \Downarrow$

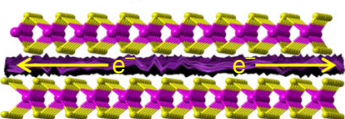

$\mathrm{Na}^{+}$storage

Fig. 3 Schematic illustration of the preparation of $\mathrm{MoS}_{2} @ C N F I G$ hybrid and sodium ions storage. a Schematic illustration of the homogeneous deposition of layered $\mathrm{MoS}_{2}$ nanoflakes on CNFIG matrix, b porous morphology of $\mathrm{MoS}_{2} @ C N F I G$ hybrid accelerates the rapid penetration of electrolyte, and $\mathbf{c}$ quick sodiation/desodiation and large sodium ions storage capabilities of $\mathrm{MoS}_{2} @ \mathrm{CNFIG}$ hybrid due to excellent electrical conductivity

and the CNF bridges. Here, the vertically aligned channels in the $\mathrm{MoS}_{2} @ \mathrm{CNFIG}$ hybrid ensure rapid penetration of the electrolyte and also contribute to the rapid transfer of sodium ions (Fig. 3b). The excellent electrical conductivity of CNFIG matrix can also provide effective pathways for fast electron transportation (Fig. 3c), which will benefit the insertion/extraction of sodium ions.

The vertically aligned channels created inside the $3 \mathrm{D}$ carbonic CNFIG networks are integrally maintained in the developed $\mathrm{MoS}_{2} @ \mathrm{CNFIG}$ nanohybrid (Fig. 4a). SEM images focusing on the 

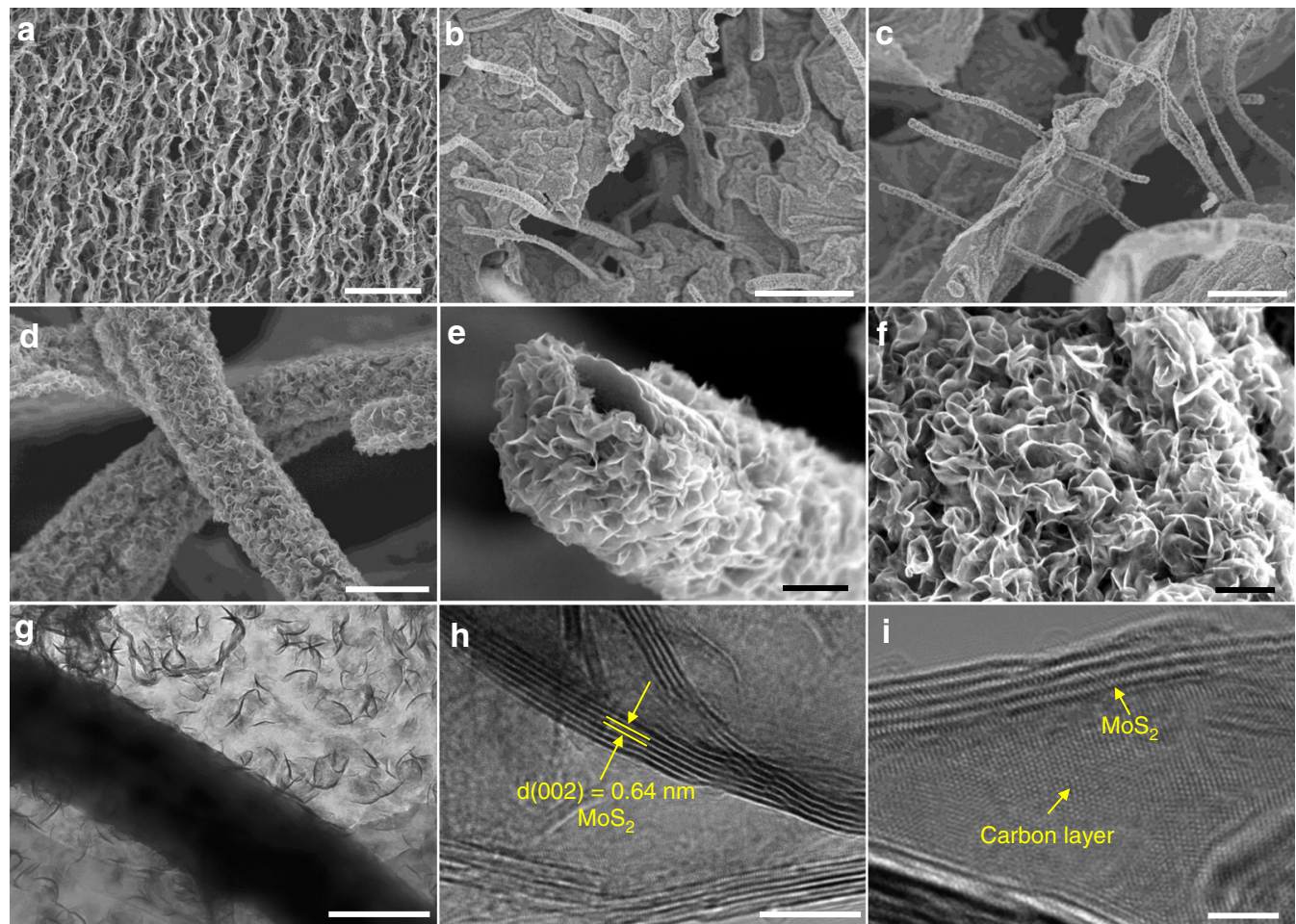

Fig. 4 SEM analysis of the as-prepared MoS ${ }_{2} @ C N F I G:$ SEM images of a overall structure (scale bar $=50 \mu \mathrm{m}$ ) and $\mathbf{b}$, c cross section of MoS $@$ CNFIG hybrid (scale bars, b $10 \mu \mathrm{m} ; \mathbf{c} 5 \mu \mathrm{m}$ ); d MoS 2 layers homogeneously anchored on the CNF bridges (scale bar $=2 \mu \mathrm{m}$ ); e SEM image of an endpoint of CNF coated with $\mathrm{MoS}_{2}$ nanoflakes (scale bar=1 $\mu \mathrm{m}$ ); $\mathbf{f}$ SEM image of selected area of $\mathrm{MoS}_{2} @ C N F I G$ hybrid with $\mathrm{MoS}_{2}$ nanoflakes anchored on the carbon layers (scale bar =500 nm); $\mathbf{g}$ TEM analysis of the $\mathrm{MoS}_{2} @ C N F I G$ sample (scale bar $=500 \mathrm{~nm}$ ); $\mathbf{h}$, $\mathbf{i}$ HRTEM images with distinctive layer spacing of MoS 2 and carbon matrix (scale bars, h $10 \mathrm{~nm} ; \mathbf{i} 2 \mathrm{~nm}$ )

cross section of the $\mathrm{MoS}_{2} @ \mathrm{CNFIG}$ hybrid further demonstrate that the CNFs are vertically aligned with the carbon layers (Fig. 4b, c). This result confirms the stable architecture with porous channels within the $\mathrm{MoS}_{2} @ \mathrm{CNFIG}$ hybrid. The homogeneously deposited $\mathrm{MoS}_{2}$ skins on the surface of the carbon layers and the CNFs are clearly illustrated by the SEM image at high magnification (Fig. 4d). The $\mathrm{MoS}_{2}$ nanomaterials possess good porous structures and "nanoflake" morphologies, contributing to a much higher specific surface area of $\mathrm{MoS}_{2} @ \mathrm{CNFIG}$ hybrid $\left(310 \mathrm{mg}^{-1}\right)$ compared with pure $\mathrm{MoS}_{2}\left(92 \mathrm{mg}^{-1}\right)$ (Supplementary Fig. 12), which can further permit complete utilization of their active sites during the charge/discharge process. In this work, the thickness of the $\mathrm{MoS}_{2}$ skin is about $200 \mathrm{~nm}$, which can be obtained from the endpoint of a CNF pillar coated by $\mathrm{MoS}_{2}$ nanoflakes (Fig. 4e). Furthermore, the carbon layers are also completely wrapped by the homogeneously deposited $\mathrm{MoS}_{2}$ layers (Fig. 4f). MoS $@$ CNFIG hybrid aerogel can be cut into round pieces with an average thickness of $2.5 \mathrm{~mm}$ (Supplementary Fig. 13), which can be directly used as anode for LIBs. In this $\mathrm{MoS}_{2} @ \mathrm{CNFIG}$ hybrid aerogel, the large voids among the graphene layers can play two roles on the battery performance (i.e., specific capacity and rate capability). On one hand, as indicated by the examiner, the voids among the graphene layers could reduce the tap density and therefore lower the volumetric energy density. On the other hand, since it is widely recognized that sodium ion have a much larger size than lithium ion, the voids in the CNFIG architecture provide the space to grow $\mathrm{MoS}_{2}$ nanoflakes, offer ample pathways for the mass transport and storage of large sodium ions, tolerate the volume changes during charge/discharge processes.

From these SEM observations, we notice that (i) the good porous structure of the CNFIG matrix is maintained, (ii) $\mathrm{MoS}_{2}$ nanomaterials with 2D flake-like geometry are homogeneously deposited on the surface of CNFIG without any aggregation, and (iii) the thin $\mathrm{MoS}_{2}$ layers are in tight contact with the CNFIG matrix which can greatly decrease the interfacial resistance for the $\mathrm{MoS}_{2} @ \mathrm{CNFIG}$ hybrid. These structural characteristics can facilitate the rapid transmission of ions and electrons contributing to the outstanding electrochemical performances of the $\mathrm{MoS}_{2} @ \mathrm{CNFIG}$ hybrid. In comparison, randomly arranged CNFs/graphene sheets/MoS 2 (CNF/G/MoS 2 ) composites without vertically aligned pores exhibit aggregated morphologies, as seen in Supplementary Fig. 14. Also, pure $\mathrm{MoS}_{2}$ materials exhibit "sphere" morphologies with a diameter of $2 \mu \mathrm{m}$ (Supplementary Fig. 15) wherein a large number of their active sites are closely wrapped inside the $\mathrm{MoS}_{2}$ spheres, potentially unused during the electrochemical reaction processes.

Transmission electron microscopy (TEM) and high-resolution TEM (HRTEM) were used to further investigate the morphological features and crystal structures of the $\mathrm{MoS}_{2} @ \mathrm{CNFIG}$ hybrid. The TEM images of $\mathrm{MoS}_{2} @ \mathrm{CNFIG}$ at low magnification (Fig. 4g) demonstrate the successful hybridization of CNFs, carbon layers and $\mathrm{MoS}_{2}$ nanoflakes. The MoS 2 nanomaterials with a $2 \mathrm{D}$ flakelike morphology are homogeneously anchored on the surface of CNFs and carbon layers without any aggregation. This suggests that the synthesis strategy developed in this work ensures a quasiepitaxial growth of $\mathrm{MoS}_{2}$ along the 1D CNFs and 2D carbon layers. The large number of pores (Supplementary Fig. 16a), permit exploitation of all the $\mathrm{MoS}_{2}$ active sites during the sodium ion insertion/extraction process. Meanwhile, the semitransparent $\mathrm{MoS}_{2}$ layers (Supplementary Fig. 16b) indicate that the anchored $\mathrm{MoS}_{2}$ nanoflakes consist of only a few layers without severe restacking. The thickness of the $\mathrm{MoS}_{2}$ layer is about or $<200 \mathrm{~nm}$ (Supplementary Fig. 17), which is consistent with the SEM result 
(Fig. 4e). The thin layer geometry of $\mathrm{MoS}_{2}$ nanoflakes can be also confirmed by the HRTEM images (Fig. $4 \mathrm{~h}, \mathrm{i}$ ), in which 4-8 layers of $\mathrm{MoS}_{2}$ with an expanded $d$-spacing of $0.64 \mathrm{~nm}$ can be detected. The tight contact between carbon layers and the anchored $\mathrm{MoS}_{2}$ nanoflakes is also confirmed by these HRTEM images. The carbon matrix with a typical $d$-spacing of $0.34 \mathrm{~nm}$, corresponding to the (002) crystal phase, is homogeneously hybridized with the introduced $\mathrm{MoS}_{2}$ nanoflakes.

Energy-dispersive X-ray (EDX) analysis was conducted to confirm the uniform deposition of $\mathrm{MoS}_{2}$ on the carbonic CNFIG networks (Supplementary Fig. 18). The SEM image of the selected cross section of $\mathrm{MoS}_{2} @ \mathrm{CNFIG}$ is presented in Supplementary Fig. $18 \mathrm{a}$ and the corresponding EDX elemental distributions of $\mathrm{C}, \mathrm{S}$, and Mo elements are presented in Supplementary Fig. 18b-d, respectively. These elemental mappings indicate the successful hybridization of $\mathrm{MoS}_{2}$ nanoflakes and the CNFIG networks with homogeneous distribution. Here, the poor $\mathrm{C}$ element signals can be ascribed to the carbon networks being completely enclosed by the homogeneously anchored $\mathrm{MoS}_{2}$ nanoflakes. Supplementary Fig. 19 exhibits the XRD patterns of the CNFIG framework, pure $\mathrm{MoS}_{2}$ and the $\mathrm{MoS}_{2} @ \mathrm{CNFIG}$ hybrid. The pure CNFIG matrix exhibits a broad diffraction peak at around $25.9^{\circ}$, which is related to the (002) crystal plane of the carbon materials ${ }^{46}$. The diffraction peaks of pure $\mathrm{MoS}_{2}$ can be indexed to the hexagonal phase of $\mathrm{MoS}_{2}$ material (JCPDS No. 37-1492). Similar diffraction peaks at $14.02^{\circ}, 33.28^{\circ}$, and $58.52^{\circ}$ detected in the XRD patterns of the $\mathrm{MoS}_{2} @ \mathrm{CNFIG}$ hybrid can be assigned to the (002), (100), and (110) planes of $\mathrm{MoS}_{2}$ crystals ${ }^{47,48}$. Here, the diffraction peak at $14.02^{\circ}$ corresponds to an interlayer spacing of $0.64 \mathrm{~nm}$, which is a little larger than that of other reported $\mathrm{MoS}_{2}$ materials $(0.62 \mathrm{~nm})^{49}$. Thus, the expanded $d$-spacing of $\mathrm{MoS}_{2}$ in the $\mathrm{MoS}_{2} @ \mathrm{CNFIG}$ hybrid can efficiently improve the insertion/extraction kinetics of sodium ions. Thermogravimetric analysis (TGA) measurement was conducted to determine the weight percentage of $\mathrm{MoS}_{2}$ materials in the developed $\mathrm{MoS}_{2} @ \mathrm{CNFIG}$ hybrid (Supplementary Fig. 20). The slight weight loss before $200{ }^{\circ} \mathrm{C}$ can be ascribed to water evaporation. The apparent decreasing curve between 240 and $405^{\circ} \mathrm{C}$ indicates the oxidation of $\mathrm{MoS}_{2}$ to $\mathrm{MoO}_{3}$. The combustion of carbon matrix occurred between 405 and $520^{\circ} \mathrm{C}$, and the weight loss at temperatures higher than $670^{\circ} \mathrm{C}$ was due to the evaporation of $\mathrm{MoO}_{3}$ in air ${ }^{50}$. Here, the weight percentage of $\mathrm{MoS}_{2}$ in the $\mathrm{MoS}_{2} @ \mathrm{CNFIG}$ hybrid is calculated to be approximately $88.0 \mathrm{wt} \%$.

Electrochemical properties. The electrochemical properties of the $\mathrm{MoS}_{2} @ \mathrm{CNFIG}$ hybrid and pure $\mathrm{MoS}_{2}$ were evaluated by assembled coin cells with pure sodium metal as the counter electrode, and pure $\mathrm{MoS}_{2}$ or $\mathrm{MoS}_{2} @ \mathrm{CNFIG}$ hybrid as the anode materials (Fig. 5). Figure 5a presents the cyclic voltammograms (CVs) of the $\mathrm{MoS}_{2} @ \mathrm{CNFIG}$ hybrid at $0.1 \mathrm{mV} \mathrm{s}^{-1}$ in the 1st, 2nd, and 5 th cycles between 0.1 and $3.0 \mathrm{~V}$. The reduction process of $\mathrm{MoS}_{2}$ can be divided into two steps: (i) the insertion of sodium ions into $\mathrm{MoS}_{2}$ interlayers (Eq. 1) and (ii) the conversion of $\mathrm{MoS}_{2}$ to Mo accompanied by the formation of $\mathrm{Na}_{2} \mathrm{~S}$ (Eq. 2) (1,52 $^{5}$.

$$
\begin{gathered}
\mathrm{MoS}_{2}+\mathrm{xNa}^{+}+\mathrm{xe}^{-}=\mathrm{Na}_{\mathrm{x}} \mathrm{MoS}_{2} \\
\mathrm{Na}_{\mathrm{x}} \mathrm{MoS}_{2}+(4-\mathrm{x}) \mathrm{Na}^{+}+(4-\mathrm{x}) \mathrm{e}^{-}=2 \mathrm{Na}_{2} \mathrm{~S}+\mathrm{Mo}
\end{gathered}
$$

In the first cathodic scan, a strong peak observed at $0.6 \mathrm{~V}$ is associated with $\mathrm{Na}^{+}$insertion into the $\mathrm{MoS}_{2}$ interlayer spacing according to Equation 1, and the formation of a solid electrolyte interface (SEI) layer owing to the decomposition of the electrolyte ${ }^{53}$. The peak under $0.5 \mathrm{~V}$ in the deep cathodic process can be assigned to the electrochemical decomposition of $\mathrm{MoS}_{2}$ to form metallic (Mo) nanograins and amorphous $\mathrm{Na}_{2} \mathrm{~S}$ matrix according to Eq. $2^{54}$. Also, a broad anodic peak at $1.75 \mathrm{~V}$ observed in the first charging process, can be ascribed to the oxidation of Mo nanograins to $\mathrm{MoS}_{2}{ }^{55}$. The CV curves in the 2nd and 5th cycles almost overlapped, suggesting high reversibility and good cycling stability of sodium ions storage in this $\mathrm{MoS}_{2} @ \mathrm{CNFIG}$ hybrid.

Discharge/charge curves for the 1st, 2nd, and 5th cycles at a constant current density of $0.1 \mathrm{~A} \mathrm{~g}^{-1}$ are shown in Fig. 5b. The initial discharge curve possesses a long plateau between 0.5 and $1.0 \mathrm{~V}$, which is consistent with the large cathodic peak at about $0.6 \mathrm{~V}$ in the first CV curve. The $\mathrm{MoS}_{2} @ \mathrm{CNFIG}$ hybrid exhibits a highly reversible specific capacity of $598 \mathrm{mAh} \mathrm{g}^{-1}$ at $0.1 \mathrm{Ag}^{-1}$ based on the total mass of $\mathrm{MoS}_{2}$ and CNFIG matrix. A recovered charge capacity of $585 \mathrm{mAh} \mathrm{g}^{-1}$ can also be observed, indicating a high Coulombic efficiency of $\sim 97.8 \%$ in the 2 nd cycle. The in situ growth of $\mathrm{MoS}_{2}$ nanoflakes with intimate contact between $\mathrm{MoS}_{2}$ nanoflakes and the CNFIG matrix has effectively avoided irreversible capacity. The good reversible ability of sodium ions in this $\mathrm{MoS}_{2} @ \mathrm{CNFIG}$ hybrid is further confirmed by the superstable discharge/charge plateaus in the 2nd and 5th cycles (Fig. 5b). However, the coarse CV curves of pure $\mathrm{MoS}_{2}$ (Supplementary Fig. 21) with much lower current intensities indicate inferior sodium ions storage capabilities. Also, a much lower specific capacity of $253 \mathrm{mAh} \mathrm{g}^{-1}$ for pure $\mathrm{MoS}_{2}$ is observed from its discharge/charge curves (Supplementary Fig. 22). The obvious decrease in the specific capacities in the 2 nd $\left(219 \mathrm{mAh} \mathrm{g}^{-1}\right)$ and 5 th $\left(179 \mathrm{mAh} \mathrm{g}^{-1}\right)$ cycles for pure $\mathrm{MoS}_{2}$ further confirms its poor reversible capability for sodium ions storage.

The rate capacities can be used to demonstrate the sodium ion storage capabilities of the $\mathrm{MoS}_{2} @ \mathrm{CNFIG}$ hybrid at low and high current densities. The $\mathrm{MoS}_{2} @ \mathrm{CNFIG}$ hybrid exhibits reversible capacities of $594,533,498,477$, and $456 \mathrm{mAh} \mathrm{g}^{-1}$ at current densities of $0.1,0.5,1.0,2.0$, and $5.0 \mathrm{~A} \mathrm{~g}^{-1}$, respectively (Fig. $5 \mathrm{c}$ ). More than $77 \%$ of the specific capacity observed at $0.1 \mathrm{~A} \mathrm{~g}^{-1}$ is maintained when the current density is increased to $5.0 \mathrm{Ag}^{-1}$, indicating that the $\mathrm{MoS}_{2} @ \mathrm{CNFIG}$ hybrid is a good anodic candidate at low and high current densities. More importantly, a high specific capacity of $582 \mathrm{mAh} \mathrm{g}^{-1}$ can be achieved when the current density is returned to $0.1 \mathrm{Ag}^{-1}$ after being cycled at high rates. This superior rate performance results from the excellent structural stability with the assistance of the inserted CNF pillars, and the intimate contact between $\mathrm{MoS}_{2}$ and the conductive CNFIG matrix with greatly shortened sodium ion diffusion distances. The Coulombic efficiencies of the $\mathrm{MoS}_{2} @ \mathrm{CNFIG}$ hybrid gradually increase after the initial capacity loss, and quickly approach $100 \%$ after several cycles, indicating good reversibility. Comparatively, pure $\mathrm{MoS}_{2}$ spheres exhibit a specific capacity of $253 \mathrm{mAh} \mathrm{g}^{-1}$ at $0.1 \mathrm{~A} \mathrm{~g}^{-1}$ and a much lower capacity of $32 \mathrm{mAh} \mathrm{g}^{-1}$ when the current density is increased to $5.0 \mathrm{~A} \mathrm{~g}^{-1}$. This inferior rate performance of pure $\mathrm{MoS}_{2}$ can be ascribed to its heavy aggregation morphology that results in serious structural collapse after several cycles. The superior rate capability of the $\mathrm{MoS}_{2} @ \mathrm{CNFIG}$ hybrid can be further confirmed by the stable discharge/charge voltage profiles at $0.1,0.5,1.0,2.0$, and $5.0 \mathrm{Ag}^{-1}$ (Fig. 5d).

The electrochemical impedance spectra (EIS) of the $\mathrm{MoS}_{2} @ \mathrm{CNFIG}$ hybrid and pure $\mathrm{MoS}_{2}$ are presented in Fig. 5e. All the impedance measurements are made at the fully discharged state after 10 cycles. The impedance spectrum of the $\mathrm{MoS}_{2} @ \mathrm{CN}$ FIG hybrid is composed of a depressed semicircle in highmedium frequencies and a straight line in low frequencies. The non-symmetrical semicircle at high-medium frequencies consists of two parts, the resistance of SEI film $\left(R_{\mathrm{s}}\right)$ and charge transfer resistance $\left(R_{\mathrm{ct}}\right)^{56}$. The sloping line in the low frequency is associated with the diffusion kinetics of $\mathrm{Na}^{+}$in active materials ${ }^{53}$. 

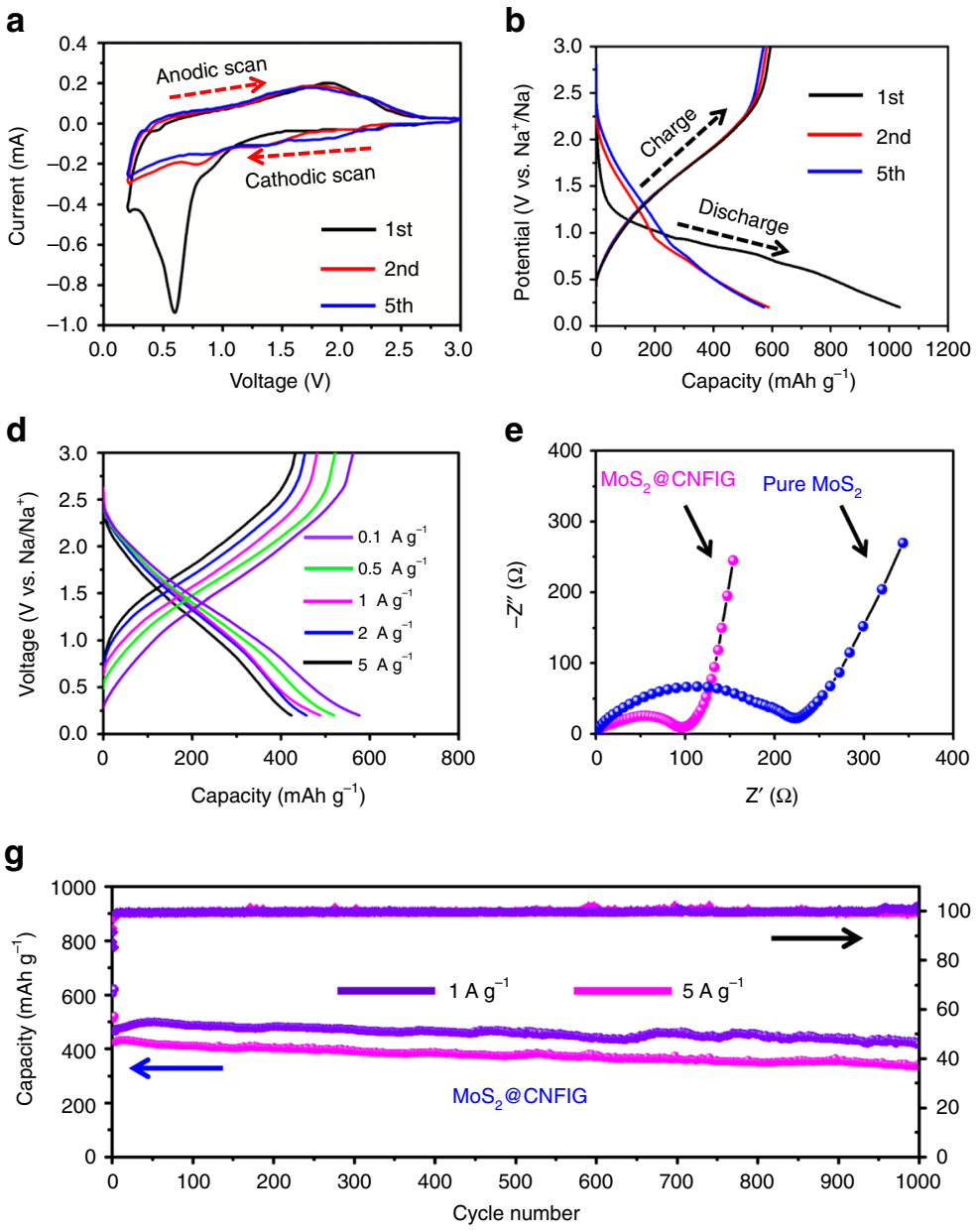
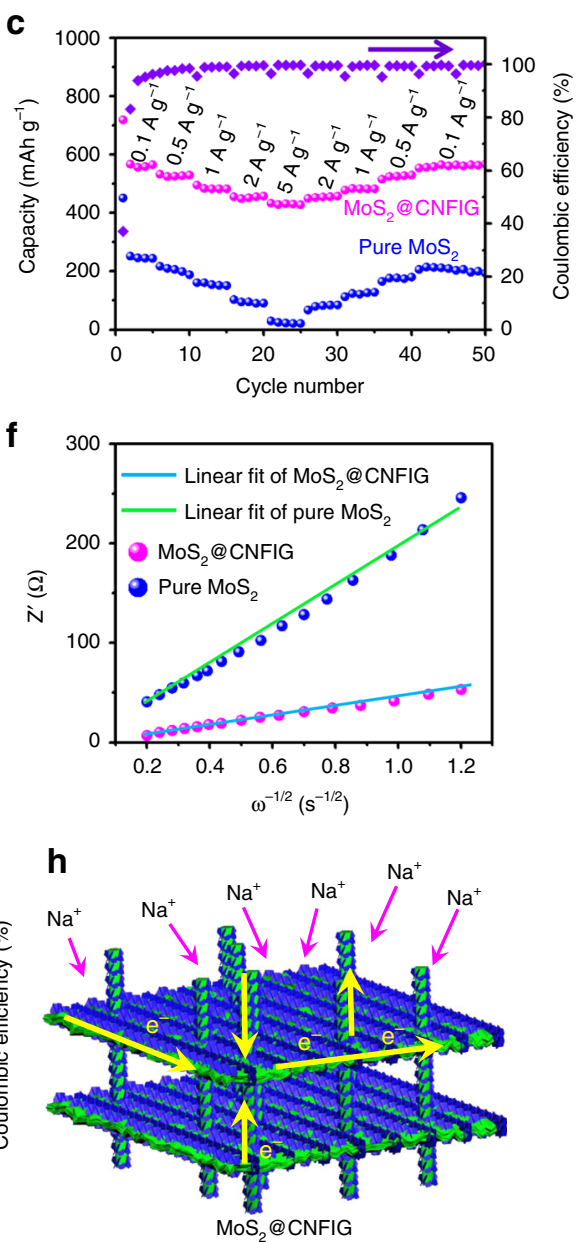

Fig. 5 Electrochemical performances of $\mathrm{MoS}_{2} @ \mathrm{CNFIG} \mathrm{hybrid} \mathrm{and} \mathrm{pure} \mathrm{MoS}_{2}$. a CV curves at $0.1 \mathrm{mV} \mathrm{s}^{-1}$ and $\mathbf{b}$ discharge/charge curves at $0.1 \mathrm{Ag}-1$ of $\mathrm{MoS}_{2} @$ CNFIG in the 1st, 2nd, and 5th cycles; c rate performances of pure $\mathrm{MoS}_{2}$ and $\mathrm{MoS}_{2} @ C N F I G$ hybrid from 0.1 to $5 \mathrm{Ag}^{-1}$; d discharge/charge curves of $\mathrm{MoS}_{2} @ \mathrm{CNFIG}$ hybrid at different current densities; e Nyquist plots of the pure $\mathrm{MoS}_{2}$ and $\mathrm{MoS}_{2} @ C N F I G$ after being cycled 5 times at $0.1 \mathrm{Ag} \mathrm{g}^{-1} ; \mathbf{f}$ the $\mathrm{Z}^{\prime}-\omega$ $-1 / 2$ curves in the low-frequency region of Nyquist plots for pure $\mathrm{MoS}_{2}$ and $\mathrm{MoS}_{2} @ C N F I G$ hybrid, respectively; $\mathbf{g}$ long-term cycling performances of $\mathrm{MoS}_{2} @ \mathrm{CNFIG}$ at 1.0 and $5.0 \mathrm{~A} \mathrm{~g}^{-1}$ and their corresponding Coulombic efficiencies; h schematic illustration of the Na+ storage mechanism and electronic conductivity in the $\mathrm{MoS}_{2} @$ CNFIG hybrid with stable "interpenetrating networks"

Here, the kinetic parameters can be obtained from the equivalent circuit (Supplementary Fig. 23) which was utilized for fitting the EIS spectra. The $\mathrm{MoS}_{2} @ \mathrm{CNFIG}$ hybrid exhibits a much lower $R_{\mathrm{ct}}$ value $(100 \Omega)$ than that of pure $\operatorname{MoS}_{2}(234 \Omega)$, indicating its higher electronic/ionic conductivity. Here, the Warburg impedance data in the low-frequency region of the Nyquist plots are utilized to analyze the chemical diffusion coefficient of sodium ions. Figure $5 f$ shows the fitted line of $Z^{\prime}-\omega^{-1 / 2}(\omega=2 \pi f)$ in the low frequencies. The lower slope $(\sigma=33.4)$ of the $\mathrm{MoS}_{2} @ \mathrm{CNFIG}$ hybrid compared to pure $\mathrm{MoS}_{2}(\sigma=242.3)$ indicates the superior insertion/extraction kinetics of sodium ions in the $\mathrm{MoS}_{2} @ \mathrm{CNFIG}$ electrode.

Long-term cycling behaviors of the $\mathrm{MoS}_{2} @ \mathrm{CNFIG}$ hybrid are shown in Fig. 5g. Here, coin cells with $\mathrm{MoS}_{2} @ \mathrm{CNFIG}$ anodes exhibit excellent long-term cycling stability at $1 \mathrm{Ag}^{-1}$. The specific capacities of the $\mathrm{MoS}_{2} @$ CNFIG hybrid are slightly increased in the first 40 cycles due to the chemical activation of the $\mathrm{MoS}_{2}$ nanoflake active sites in the $\mathrm{MoS}_{2} @$ CNFIG hybrid. The $\mathrm{MoS}_{2} @ \mathrm{CNFIG}$ hybrid exhibits a sustainable specific capacity of $412 \mathrm{mAh} \mathrm{g}^{-1}$ in the 1000th cycle, delivering capacity retention of $86.2 \%$ based on its initial specific capacity $\left(478 \mathrm{mAh} \mathrm{g}^{-1}\right)$ in the 2nd cycle. More importantly, the $\mathrm{MoS}_{2} @ \mathrm{CNFIG}$ hybrid also exhibits a promising cycling life even at high current density of $5 \mathrm{Ag}^{-1}$. A reversible specific capacity of $366 \mathrm{mAhg}^{-1}$ was achieved at $5 \mathrm{Ag}^{-1}$ after 1000 cycles, achieving capacity retention of $86.9 \%$. The $\mathrm{MoS}_{2} @$ CNFIG hybrid also achieves high Coulombic efficiencies approaching $\sim 100 \%$ both at 1 and $5 \mathrm{Ag} \mathrm{g}^{-1}$, indicating the excellent reversible insertion/extraction ability of sodium ions inside its interpenetration networks. Comparatively, pure $\mathrm{MoS}_{2}$ exhibits a sharp capacity decrease in the first 100 cycles (Supplementary Fig. 24). A much lower specific capacity of $34 \mathrm{mAh} \mathrm{g}^{-1}$ is obtained after 1000 cycles with poor Coulombic efficiencies. Herein, the excellent sodium ions storage properties of the $\mathrm{MoS}_{2} @ \mathrm{CNFIG}$ hybrid can be ascribed to its hierarchical geometry with aligned channels, high electronic/ionic conductivity and uniform dispersion of thin $\mathrm{MoS}_{2}$ layers. The introduced CNFs acting as the supporting pillars are beneficial for maintaining the structural integrity of the $\mathrm{MoS}_{2} @ \mathrm{CNFIG}$ hybrid by suppressing the stacking of $\mathrm{MoS}_{2}$ nanoflakes, resulting in its superior electrochemical stability. The excellent porous structures with stable channels and the perfect electronic/ionic conductivity achieved by the $\mathrm{MoS}_{2} @ \mathrm{CNFIG}$ hybrid ensure the reversible insertion/extraction of sodium ions at a large scale, which promotes the exploitation of all the active sites of $\mathrm{MoS}_{2}$ nanoflakes in rapid charge/discharge processes.

A CNF/G/MoS 2 composite was also used an anode material to fabricate the sodium cell, to examine its electrochemical activity for sodium ions storage. This randomly arranged $\mathrm{CNF} / \mathrm{G} / \mathrm{MoS}_{2}$ 
composite without any aligned channels exhibits comparable specific capacities ( $584 \mathrm{mAhg}^{-1}$ ) to that of the $\mathrm{MoS}_{2} @ \mathrm{CNFIG}$ hybrid at low current density of $0.1 \mathrm{~A} \mathrm{~g}^{-1}$ (Supplementary Fig. 25). However, when the testing current density is increased to $5.0 \mathrm{~A} \mathrm{~g}^{-1}$, the sodium ions storage capability of the CNF/G/ $\mathrm{MoS}_{2}$ composite is severely decreased to $120 \mathrm{mAh} \mathrm{g}^{-1}$, as confirmed by its rate performance (Supplementary Fig. 26). This poor performance of the $\mathrm{CNF} / \mathrm{G} / \mathrm{MoS}_{2}$ composite can be ascribed to the absence of efficient aligned channels and the unexpected utilization of the non-conducting polymer binder of PVDF. Furthermore, this $\mathrm{CNF} / \mathrm{G} / \mathrm{MoS}_{2}$ composite also shows an inferior long-term cycling life, with only $55 \%$ of its initial specific capacity maintained (Supplementary Fig. 27). Comparison of the electrochemical performances of the CNF/G/MoS 2 composite with those of the $\mathrm{MoS}_{2} @ \mathrm{CNFIG}$ hybrid further confirm the structural advantages of the vertically aligned channels and robust template matrix, which greatly contribute to the structural stability of the electrode and provide efficient pathways for the transfer of sodium ions and electrons. The EIS spectra of sodium ions cells with $\mathrm{CNF} / \mathrm{G} / \mathrm{MoS}_{2}$ composite anodes are presented in Supplementary Fig. 28. A higher $R_{\mathrm{ct}}$ value $(166 \Omega)$ of the $\mathrm{CNF} / \mathrm{G} / \mathrm{MoS}_{2}$ composite demonstrates a larger charge transfer resistance. Here, the $R_{\mathrm{ct}}$ value $\left(166 \Omega\right.$ ) of the $\mathrm{CNF} / \mathrm{G} / \mathrm{MoS}_{2}$ composite is lower than the pure $\mathrm{MoS}_{2}$ electrode $(234 \Omega)$, due to the introduced graphene sheets template that restricts the restacking of the $\mathrm{MoS}_{2}$ nanoflakes, and the inserted CNFs that increase the internal electrical conductivity. The higher slope $(\sigma=92.3)$ of the $\mathrm{CNF} / \mathrm{G} /$ $\mathrm{MoS}_{2}$ composite (Supplementary Fig. 29) compared with the $\mathrm{MoS}_{2} @ \mathrm{CNFIG}$ hybrid $(\sigma=33.4)$ demonstrates less efficient sodium ions transfer inside the $\mathrm{CNF} / \mathrm{G} / \mathrm{MoS}_{2}$ composite anode, which limits rapid sodium ions insertion/extraction under high current densities. Moreover, the $\mathrm{MoS}_{2} @ \mathrm{CNFIG}$ hybrid is comparable with or superior to other types of carbon/ $\mathrm{MoS}_{2}$ composites (Supplementary Fig. 30).

The structural integrity of the $\mathrm{MoS}_{2} @ \mathrm{CNFIG}$ anode after being cycled 1000 times is further confirmed by SEM imagery (Fig. 6a). The vertically aligned pores of the $\mathrm{MoS}_{2} @ \mathrm{CNFIG}$ anode are completely preserved, which can ensure efficient diffusion pathways for the electrolyte even after a long-term cycling process, and provide sufficient expansion space for $\mathrm{MoS}_{2}$ nanoflakes. All these features can undoubtedly contribute to the reversible insertion/extraction of sodium ions. EDX mapping of $\mathrm{Na}, \mathrm{Mo}$, and $\mathrm{S}$ elements can be clearly detected (Fig. 6b), confirming the stable structure of the $\mathrm{MoS}_{2} @ \mathrm{CNFIG}$ hybrid and its effective adsorption of sodium ions. The elemental map of $\mathrm{Na}$ can be ascribed to the sodium ions being adsorbed via chemical redox reactions. The mapping signal of $\mathrm{C}$ is due to the complete wrapping of the carbon shells by $\mathrm{MoS}_{2}$ nanoflakes. This result demonstrates that the anchored $\mathrm{MoS}_{2}$ nanoflakes do not fall off, even after long-term cycling, and the tight contact between $\mathrm{MoS}_{2}$ nanoflakes and the carbon shells. Figure $6 \mathrm{c}$ shows that 12 lightemitting diodes (LEDs) can be lit up by three coin cells connected in series based on $\mathrm{MoS}_{2} @ \mathrm{CNFIG}$ anodes, which further confirms the potential practical applications of the developed $\mathrm{MoS}_{2} @ \mathrm{CN}$ FIG hybrid.

To evaluate the superior long-term cycling capability coupled with a good rate performance, the $\mathrm{MoS}_{2} @$ CNFIG hybrid was first cycled at $1 \mathrm{~A} \mathrm{~g}^{-1}$ for 300 cycles then continuously cycled at high current density up to $10 \mathrm{Ag}^{-1}$ for 400 cycles (Fig. 6d). The $\mathrm{MoS}_{2} @ \mathrm{CNFIG}$ hybrid exhibits a stable cycling performance by achieving a reversible specific capacity of $322 \mathrm{mAh} \mathrm{g}^{-1}$ in the 300 th cycle at $10 \mathrm{~A} \mathrm{~g}^{-1}$ and $303 \mathrm{mAh} \mathrm{g}^{-1}$ in the 700th cycle. When the current density is returned to $1 \mathrm{Ag}^{-1}$, the $\mathrm{MoS}_{2} @ \mathrm{CN}$ FIG hybrid shows a recoverable specific capacity of $421 \mathrm{mAh} \mathrm{g}^{-1}$ and can be further cycled 300 times with high Coulombic efficiencies approaching $\sim 100 \%$. Here, the superior rate performances of $\mathrm{MoS}_{2} @ \mathrm{CNFIG}$ hybrid can be ascribed to its excellent structural stability and the ultra-high utilization efficiency of $\mathrm{MoS}_{2}$ nanoflakes due to their structural features. The EIS spectra of the $\mathrm{MoS}_{2} @ \mathrm{CNFIG}$ hybrid after being cycled two and 1000 times are presented in Fig. 6e. The increased $R_{\mathrm{ct}}$ value in the 1000 th cycle $(162.3 \Omega)$ compared with the initial result in the 2 nd cycle $(100 \Omega)$, further confirms the structural integrity and stable interfacial reaction during the long-term cycling process. The TEM image of the cycled $\mathrm{MoS}_{2} @ \mathrm{CNFIG}$ hybrid exhibits flake-like $\mathrm{MoS}_{2}$ structures (Fig. 6f) with the existence of clear lattice fringes (inset in Fig. 6f). Here, the promising electrochemical storage of sodium ions can be ascribed to the hierarchical structure of the $\mathrm{MoS}_{2} @ \mathrm{CNFIG}$ hybrid (Fig. 6g). Firstly, the nested structures produce nanoreservoirs between adjacent $\mathrm{MoS}_{2}$ nanoflakes, which favor interfacial interactions between the active sites of $\mathrm{MoS}_{2}$ and the electrolyte, and shorten the ionic diffusion pathways ${ }^{57}$. Secondly, the vertically aligned channels ensure the rapid penetration of electrolyte and sodium ions, which helps relieve the masstransfer limitations of the electrochemical $\mathrm{MoS}_{2}$-sodium ions reactions ${ }^{58}$. Thirdly, the tightly anchored $\mathrm{MoS}_{2}$ on the surface of the CNFIG matrix provides good current collector/ $\mathrm{MoS}_{2}$ electrical contact and much lower $R_{\mathrm{ct}}$ resistance. Lastly, the vertically aligned channels and the porous structure of the $\mathrm{MoS}_{2} @ \mathrm{CNFIG}$ hybrid provide sufficient volume expansion space for active $\mathrm{MoS}_{2}$ nanomaterials (Fig. 6g), avoiding the structural collapse responsible for irreversible capacities.

\section{Discussion}

In summary, we have rationally designed and successfully fabricated a 3D $\mathrm{MoS}_{2} @ \mathrm{CNFIG}$ nanohybrid with unique interpenetration networks as a free-standing anode for SIBs (without the use of conductive additives and binders). The as-prepared CNFIG framework provides ultra-stable channels and the supporting pillars between different carbon layers, facilitating efficient pathways for the rapid penetration of electrolyte and quick transfer of sodium ions. The excellent electrical conductivity of the CNFIG matrix, coupled with the robust interfacial contact between $\mathrm{MoS}_{2}$ nanoflakes and CNFIG matrix, enable low charge transfer resistance and full utilization of active sites of the anchored $\mathrm{MoS}_{2}$ electroactive materials. The ultra-high mechanical compression property of the CNFIG matrix can contribute to the structural stability of the $\mathrm{MoS}_{2} @ \mathrm{CNFIG}$ hybrid, avoiding any unexpected structural collapse from the volume expansion of $\mathrm{MoS}_{2}$ materials in charge/discharge processes. As a result, a high specific capacity of $598 \mathrm{mAh} \mathrm{g}^{-1}$ and a long-term cycling stability up to 1000 times with an average Coulombic efficiency of $\sim 100 \%$ are achieved by this $\mathrm{MoS}_{2} @ \mathrm{CNFIG}$ hybrid. Importantly, the $\mathrm{MoS}_{2} @ \mathrm{CNFIG}$ hybrid also possesses an excellent rate performance even at a high current density up to $10 \mathrm{Ag}^{-1}$ due to its unique interpenetration networks. Furthermore, this $\mathrm{MoS}_{2} @ \mathrm{CNFIG}$ hybrid provides new insights for designing and fabricating good porous electrode materials for energy storage in other fields with high capacity, long cycling life, and excellent rate performances.

\section{Methods}

Materials. Concentrated sulfuric acid $\left(\mathrm{H}_{2} \mathrm{SO}_{4}, 98 \%\right)$, thiourea $\left(\mathrm{CH}_{4} \mathrm{~N}_{2} \mathrm{~S}\right)$, hexaammonium molybdate $\left(\left(\mathrm{NH}_{4}\right)_{6} \mathrm{Mo}_{7} \mathrm{O}_{24}\right), \mathrm{N}, \mathrm{N}$-Dimethylacetamide (DMAc), triethylamine (TEA), 4,4'-oxidianiline (ODA), and pyromellitic dianhydride (PMDA) were purchased from Shanghai Chemical Reagent Company. Deionized (DI) water was used throughout the experiments.

Synthesis of PAA powders. Poly(amic acid) (PAA) powders were prepared based on ODA and PMDA. Typically, $2.15 \mathrm{~g}$ of ODA was dispersed into $27.5 \mathrm{~mL}$ of DMAc by strong stirring at $0{ }^{\circ} \mathrm{C}$. Then, PMDA $(2.35 \mathrm{~g})$ was gradually added into the mixture and the reaction was maintained for $5 \mathrm{~h}$ in an ice bath. TEA $(1.1 \mathrm{~g})$ was 
a

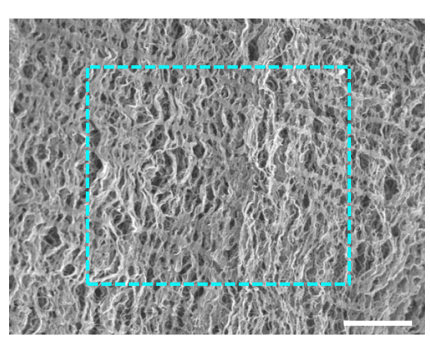

b

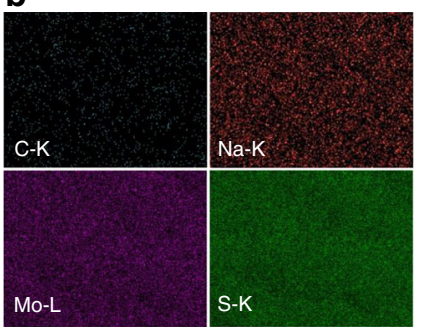

C

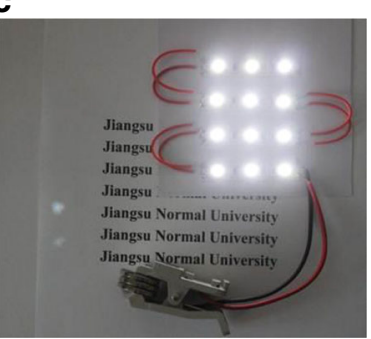

d

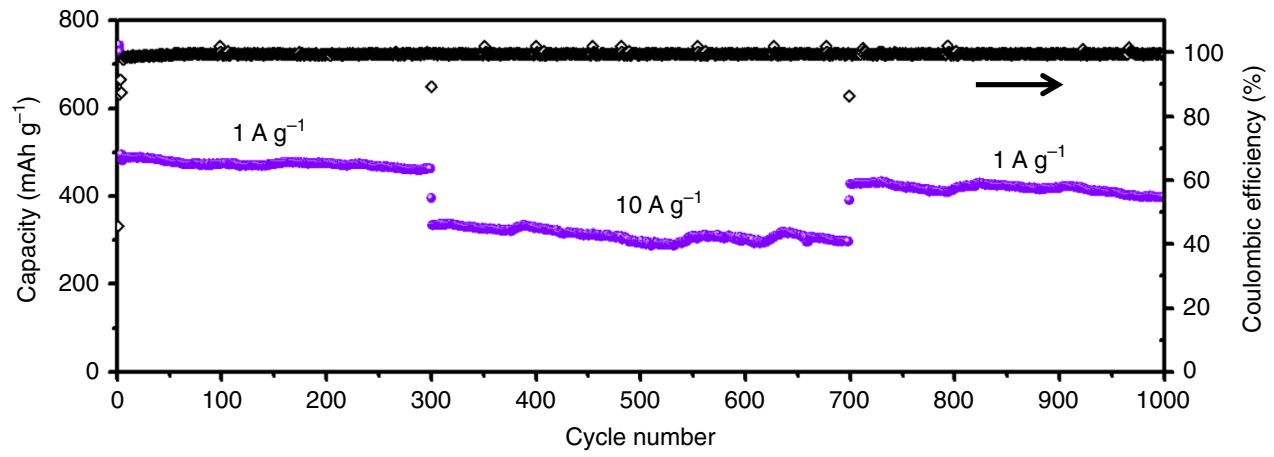

e

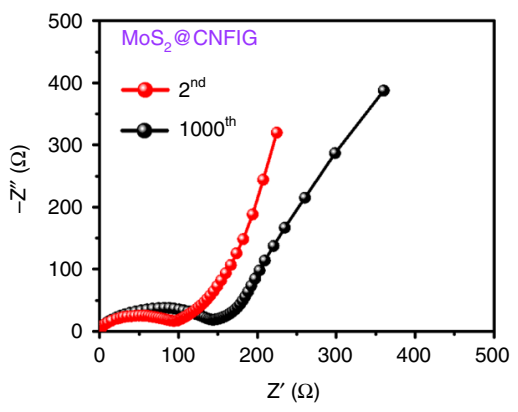

f

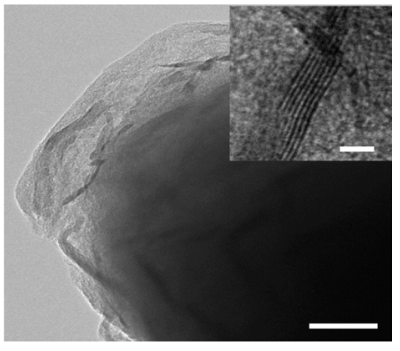

g

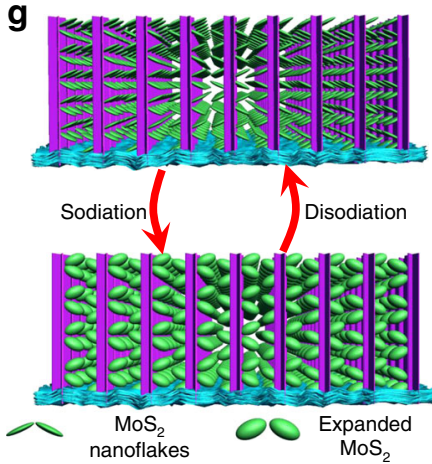

Fig. 6 The structural evolution and electrochemical performances of $\mathrm{MoS}_{2} @ C N F I G$ anode. a SEM image of MoS ${ }_{2} @ C N F I G$ anode after being cycled 1000 times (scale bar $=50 \mu \mathrm{m}$ ) and $\mathbf{b}$ corresponding EDX elemental mappings of $\mathrm{C}$, Na, Mo, and S; $\mathbf{c}$ twelve LEDs can be lit up by three coin cells connected in series based on the as-prepared $\mathrm{MoS}_{2} @ \mathrm{CNFIG}$ anodes; d long-term cycling performance of $\mathrm{MoS}_{2} @ \mathrm{CNFIG}$ at 1 and $10 \mathrm{Ag} \mathrm{g}^{-1}$; e EIS spectra of $\mathrm{MoS}_{2} @$ CNFIG hybrid after being cycled two and 1000 times; f TEM image of the MoS ${ }_{2} @ C N F I G$ hybrid cycled 1000 times (scale bar=50 nm; Scale bar for inset in $\mathbf{f}, 2 \mathrm{~nm}$ ); $\mathbf{g}$ schematic illustration of the tight contact between $\mathrm{MoS}_{2}$ nanoflakes and the carbon shells, as well as the good porous space provided by the $\mathrm{MoS}_{2} @ C N F I G$ hybrid for the volume expansion of $\mathrm{MoS}_{2}$ nanoflakes

dropped into the mixture drop-by-drop. After $5 \mathrm{~h}$, a yellow viscous solution TEAPAA, was obtained and poured into DI water. The precipitate was washed several times by DI water then freeze-dried, resulting in the formation of yellow PAA powders.

Synthesis of CNF. The reaction product based on ODA and PMDA prior to the addition of TEA can be directly used as a polymer matrix for electrospinning with a weight percent of $\sim 15 \%$. Electrospinning was carried out at an applied voltage of $12-18 \mathrm{kV}$ with a feeding speed of $0.5 \mathrm{~mL} \mathrm{~h}^{-1}$ with a distance of $18 \mathrm{~cm}$ between the syringe and the aluminum collector. The obtained PAA film was carbonized at $300^{\circ} \mathrm{C}$ in air for $2 \mathrm{~h}$ and at $900^{\circ} \mathrm{C}$ in $\mathrm{Ar}$ for $5 \mathrm{~h}$, resulting in the formation of carbon nanofiber film. The obtained carbon nanofiber film was immersed into $\mathrm{H}_{2} \mathrm{SO}_{4}$ for 3 days, and further treated with strong sonication for $60 \mathrm{~min}$ following by washing with DI water, producing CNFs. For short CNFs with an average length of $2-3 \mu \mathrm{m}$, the obtained long CNFs were further treated with ball-milling at $400 \mathrm{rpm}$ for $4 \mathrm{~h}$.

Preparation of CNFIG. GO materials were prepared according to a modified Hummers' method $^{39}$. CNFs $(100 \mathrm{mg})$ were dispersed into a GO solution $(200 \mathrm{~mL}$, $\left.1 \mathrm{mg} \mathrm{mL}^{-1}\right)$ under strong stirring and sonication. Then, PAA powder $(0.4 \mathrm{~g})$ was dispersed into the mixture with the assistance of TEA $(2 \mathrm{~mL})$. The obtained mixture was vertically frozen with the bottom of the container gradually immersed into liquid nitrogen. The frozen $\mathrm{GO} / \mathrm{CNF} / \mathrm{PAA}$ composite was freezedried at $-50^{\circ} \mathrm{C}$ under $10 \mathrm{~Pa}$, and the obtained GO/CNF/PAA aerogel was further carbonized at $900^{\circ} \mathrm{C}$ in $\mathrm{Ar}$ for $5 \mathrm{~h}$, resulting in the formation of CNFinterpenetrated graphene, named as CNFIG.

Preparation of $\mathbf{M o S}_{\mathbf{2}} @ \mathbf{C N F I G} .\left(\mathrm{NH}_{4}\right)_{6} \mathrm{Mo}_{7} \mathrm{O}_{24}(1.5 \mathrm{mmol})$ and $\mathrm{CH}_{4} \mathrm{~N}_{2} \mathrm{~S}(21$ mmol) were dissolved into $40 \mathrm{ml}$ of ultrapure water, and $200 \mathrm{mg}$ of CNFIG cake were put into the solution. The resultant mixture was subjected to a hydrothermal reaction at $220^{\circ} \mathrm{C}$ for $12 \mathrm{~h}$ in a Teflon-lined stainless steel autoclave $(50 \mathrm{~mL})$. The obtained dry solid materials were high-temperature treated at $700^{\circ} \mathrm{C}$ for $2 \mathrm{~h}$, resulting in $\mathrm{MoS}_{2} @ \mathbf{C N F I G}$ active materials. Pure $\mathrm{MoS}_{2}$ materials were prepared according to the same method without the addition of the CNFIG matrix.

Preparation of CNF/G/MoS . CNFs (100 mg), GO sheets (200 mg) and PAA matrix $(0.4 \mathrm{~g})$ were firstly co-dispersed with the assistance of strong sonication $(1000 \mathrm{~W}, 40 \mathrm{KHz})$. And these CNFs/GO/PAA composite were dried in the oven at $80^{\circ} \mathrm{C}$ overnight, and were further carbonized in the furnace tube at $900{ }^{\circ} \mathrm{C}$ for $5 \mathrm{~h}$ in $\mathrm{Ar}$, achieving the development of $\mathrm{CNFs} /$ graphene sheets $(\mathrm{CNF} / \mathrm{G})$ composite powder. Then, $\left(\mathrm{NH}_{4}\right)_{6} \mathrm{Mo}_{7} \mathrm{O}_{24}(1.5 \mathrm{mmol})$ and $\mathrm{CH}_{4} \mathrm{~N}_{2} \mathrm{~S}(21 \mathrm{mmol})$ were dissolved into $40 \mathrm{~mL}$ ultrapure water, and $200 \mathrm{mg}$ of $\mathrm{CNF} / \mathrm{G}$ powder were dispersed into the above solution. Then the resultant mixture was subjected to a Teflon-lined stainless steel autoclave $(50 \mathrm{~mL})$ and further reacted at $220^{\circ} \mathrm{C}$ for $12 \mathrm{~h}$. The obtained dry solid materials were treated at $700^{\circ} \mathrm{C}$ for $2 \mathrm{~h}$, resulting in $\mathrm{CNF} / \mathrm{G} / \mathrm{MoS}_{2}$ active materials. 
Materials characterization. The nanostructures and morphologies of the prepared IN-C matrix and $\mathrm{MoS}_{2} @ \mathrm{CNFIG}$ hybrid were studied by field-emission scanning electron microscopy (SEM, Hitachi, SU8010) and transmission electron microscopy (TEM, FEI Tecnai G2 F20). Energy dispersive X-ray spectroscopy (EDX) detections were captured with an EDAX (PW9900). The weight percent of samples were determined using thermogravimetric analysis (TGA) equipment (TA 500) from room temperature to $800^{\circ} \mathrm{C}$ with a heating rate of $10^{\circ} \mathrm{C} \mathrm{min}^{-1}$. The crystalline phases of the developed products were characterized by a XRD diffractometer (Bruker. D8 Advanced) with $\mathrm{Cu} \mathrm{Ka}=0.154056 \mathrm{~nm}$. The compression tests of $\mathrm{MoS}_{2} @ \mathrm{CNFIG}$ hybrid were performed on an electronic universal testing machine (SANS, CMT6103). Electrical conductivity was tested on an electrochemical workstation (CHI 660D).

Electrochemical measurements. Electrochemical measurements of the prepared materials were carried out by two-electrode CR2032 coin-type cells. The $\mathrm{MoS}_{2} @ \mathrm{CNFIG}$ hybrid was used as binder-free anodes, and sodium foil was used as the cathode with a microporous glass fiber separator (Whatman) placed between the sodium metal counter electrode and the working electrode. $1 \mathrm{M} \mathrm{NaClO}_{4}$ (Alfa Aesar) in (1:1 v/v) dimethyl carbonate/ethylene carbonate was used as the electrolyte. A washer, spring, and top casing were placed on top to complete the assembly before crimping. For CNF/G/MoS 2 and pure $\mathrm{MoS}_{2}$ anodes, they were mixed with conductive additions and polymer binder, and were further coated on copper foil to form the anode electrodes. For example, $\mathrm{CNF} / \mathrm{G} / \mathrm{MoS}_{2}$ (or pure $\mathrm{MoS}_{2}$ ) powders $(80 \mathrm{wt} \%$ ) were mixed with acetylene black (Super P, $10 \mathrm{wt} \%$ ) and polyvinylidene fluoride (PVDF, $10 \mathrm{wt} \%$ ) to prepare the pure $\mathrm{MoS}_{2}$ working electrodes. Cyclic voltammograms (CVs) curves of the assembled coins were tested on a BT2000 ARBIN between 0.1 and $3.0 \mathrm{~V}$ vs. $\mathrm{Na} / \mathrm{Na}^{+}$. Discharge/charge curves of the assembled coins were recorded on LAND 2001A testing systems. Electrochemical impedance spectroscopy (EIS) measurements were carried out based on a Princeton-solartron system over the frequency range $100 \mathrm{kHz}$ to $0.01 \mathrm{~Hz}$ under an open circuit potential. Here, it is necessary to declare that the calculated specific capacities of the prepared samples were based on the total mass of the $\mathrm{MoS}_{2} @$ CNFIG hybrid. The diffusion coefficient (D) of sodium ions inside the electrodes was calculated based on the EIS spectra in the low-frequency region according to the following equations:

$$
\begin{gathered}
D=\frac{R^{2} T^{2}}{2 A^{2} \mathrm{n}^{4} F^{4} C^{2} \sigma^{2}} \\
Z_{W}=\mathrm{R}_{D}+\mathrm{R}_{L}+\sigma \omega^{-1 / 2}
\end{gathered}
$$

Where $R$ is the gas constant, $T$ is the absolute temperature, $\mathrm{A}$ is the electrode area, $\mathrm{n}$ is the number of electrons per molecule during oxidization (for sodium ions, value is 1$), F$ is the Faraday constant, $C$ is the initial concentration $\left(\mathrm{mol} \mathrm{cm}^{-3}\right)$ and $\sigma$ represents the Warburg factor, which is relative to $Z w$ according to the second equation above. The Warburg factor $(\sigma)$ can be detected from the slope value based on $Z w$ with the square root of the frequency $\left(\omega^{-1 / 2}\right)$.

\section{Data availability}

The data that support the findings of this study are available from the corresponding author upon request.

Received: 20 April 2019 Accepted: 8 August 2019

Published online: 02 September 2019

\section{References}

1. Sun, J. et al. A phosphorene-graphene hybrid material as a high-capacity anode for sodium-ion batteries. Nat. Nanotech. 10, 980 (2015).

2. Vaalma, C., Buchholz, D., Weil, M. \& Passerini, S. A cost and resource analysis of sodium-ion batteries. Nat. Rev. Mater. 3, 18013 (2018).

3. $\mathrm{Xu}, \mathrm{X}$. et al. A room-temperature sodium-sulfur battery with high capacity and stable cycling performance. Nat. Commun. 9, 3870 (2018).

4. Li, G. et al. Stable metal battery anodes enabled by polyethylenimine sponge hosts by way of electrokinetic effects. Nat. Energy 3, 1076-1083 (2018).

5. Choudhury, S. et al. Designing solid-liquid interphases for sodium batteries. Nat. Commun. 8, 898 (2017)

6. Fang, Y., Yu, X.-Y. \& Lou, X. W. Formation of hierarchical Cu-doped $\mathrm{CoSe}_{2}$ microboxes via sequential ion exchange for high-performance sodium-ion batteries. Adv. Mater. 30, 1706668 (2018).

7. Zhou, G. et al. Bioinspired micro/nanofluidic ion transport channels for organic cathodes in high-rate and ultrastable lithium/sodium-ion batteries. Adv. Funct. Mater. 0, 1804629 (2018).

8. Zhao, F. et al. Improved sodium-ion storage performance of ultrasmall iron selenide nanoparticles. Nano. Lett. 17, 4137-4142 (2017).
9. You, Y. et al. Insights into the improved high-voltage performance of Liincorporated layered oxide cathodes for sodium-ion. Batter. Chem. $\mathbf{4}$, 2124-2139 (2018)

10. Chen, X. et al. Ion-solvent complexes promote gas evolution from electrolytes on a sodium metal anode. Angew. Chem. Int. Ed. 57, 734-737 (2018).

11. Cheng, X.-B., Zhang, R., Zhao, C.-Z. \& Zhang, Q. Toward safe lithium metal anode in rechargeable batteries: a review. Chem. Rev. 117, 10403-10473 (2017).

12. Xie, F., Zhang, L., Su, D., Jaroniec, M. \& Qiao, S.-Z. $\mathrm{Na}_{2} \mathrm{Ti}_{3} \mathrm{O}_{7} @ \mathrm{~N}-\mathrm{Zdoped}$ carbon hollow spheres for sodium-ion batteries with excellent rate performance. Adv. Mater. 29, 1700989 (2017).

13. Zhang, X., Li, X., Liang, J., Zhu, Y. \& Qian, Y. Synthesis of $\mathrm{MoS}_{2} @ \mathrm{C}$ nanotubes via the kirkendall effect with enhanced electrochemical performance for lithium ion and sodium ion batteries. Small 12, 2484-2491 (2016).

14. $\mathrm{Xu}$, $\mathrm{Y}$. et al. Layer-by-layer $\mathrm{Na}_{3} \mathrm{~V}_{2}\left(\mathrm{PO}_{4}\right)_{3}$ embedded in reduced graphene oxide as superior rate and ultralong-life sodium-ion battery cathode. $A d v$. Energy Mater. 6, 1600389 (2016).

15. Luo, W. et al. Na-ion battery anodes: materials and electrochemistry. Acc. Chem. Res. 49, 231-240 (2016).

16. Gao, H. et al. Integrated carbon/red phosphorus/graphene aerogel 3D architecture via advanced vapor-redistribution for high-energy sodium-ion batteries. Adv. Energy Mater. 6, 1601037 (2016).

17. Guo, Q. et al. Cobalt sulfide quantum dot embedded N/S-doped carbon nanosheets with superior reversibility and rate capability for sodium-ion batteries. ACS Nano 11, 12658-12667 (2017).

18. $\mathrm{Li}, \mathrm{Y}$. et al. Insights into the $\mathrm{Na}^{+}$storage mechanism of phosphorusfunctionalized hard carbon as ultrahigh capacity anodes. Adv. Energy Mater. 8, 1702781 (2018)

19. Park, H. et al. Unusual $\mathrm{Na}^{+}$Ion intercalation/deintercalation in metal-rich $\mathrm{Cu}_{1.8} \mathrm{~S}$ for Na-Ion batteries. ACS Nano 12, 2827-2837 (2018).

20. $\mathrm{Ni}$, J. et al. Boosting sodium storage in $\mathrm{TiO}_{2}$ nanotube arrays through surface phosphorylation. Adv. Mater. 30, 1704337 (2018).

21. Zheng, Y. et al. Boosted charge transfer in Sns/sno2 heterostructures: toward high rate capability for sodium-ion batteries. Angew. Chem. Int. Ed. 55, 3408-3413 (2016).

22. Zhu, C., Mu, X., van Aken, P. A., Yu, Y. \& Maier, J. Single-layered ultrasmall nanoplates of $\mathrm{MoS}_{2}$ embedded in carbon nanofibers with excellent electrochemical performance for lithium and sodium storage. Angew. Chem. Int. Ed. 53, 2152-2156 (2014)

23. Shen, L. et al. Ultrathin $\mathrm{Ti}_{2} \mathrm{Nb}_{2} \mathrm{O}_{9}$ nanosheets with pseudocapacitive properties as superior anode for sodium-ion batteries. Adv. Mater. 30, 1804378 (2018).

24. Jia, G., Chao, D., Tiep, N. H., Zhang, Z. \& Fan, H. J. Intercalation Na-ion storage in two-dimensional $\mathrm{MoS}_{2-\mathrm{x}} \mathrm{Se}_{\mathrm{x}}$ and capacity enhancement by selenium substitution. Energ. Storage Mater. 14, 136-142 (2018).

25. Hou, W. et al. Solid electrolytes and interfaces in all-solid-state sodium batteries: Progress and perspective. Nano Energy 52, 279-291 (2018).

26. He, J. et al. Freestanding $1 \mathrm{~T} \mathrm{MoS}_{2} /$ graphene heterostructures as a highly efficient electrocatalyst for lithium polysulfides in Li-S batteries. Energy Environ. Sci. 12, 344-350 (2019).

27. Shan, T.-T. et al. Combining nitrogen-doped graphene sheets and $\mathrm{MoS}_{2}$ : a unique film-foam-film structure for enhanced lithium storage. Angew. Chem. Int. Ed. 55, 12783-12788 (2016).

28. Tang, C., Zhong, L., Zhang, B., Wang, H.-F. \& Zhang, Q. 3D mesoporous van der waals heterostructures for trifunctional energy electrocatalysis. $A d v$. Mater. 30, 1705110 (2018).

29. Geng, X. et al. Freestanding metallic $1 \mathrm{~T} \mathrm{MoS}_{2}$ with dual ion diffusion paths as high rate anode for sodium-ion batteries. Adv. Funct. Mater. 27, 1702998 (2017).

30. Li, G. et al. Enhanced reversible sodium-ion intercalation by synergistic coupling of few-layered $\mathrm{MoS}_{2}$ and S-doped graphene. Adv. Funct. Mater. 27, 1702562 (2017)

31. Li, Y. et al. Enhancing sodium-ion battery performance with interlayerexpanded $\mathrm{MoS}_{2}-\mathrm{PEO}$ nanocomposites. Nano Energy 15, 453-461 (2015).

32. Xie, X., Ao, Z., Su, D., Zhang, J. \& Wang, G. $\mathrm{MoS}_{2}$ /graphene composite anodes with enhanced performance for sodium-ion batteries: the role of the twodimensional heterointerface. Adv. Funct. Mater. 25, 1393-1403 (2015).

33. Xiong, P., Ma, R., Sakai, N., Nurdiwijayanto, L. \& Sasaki, T. Unilamellar metallic $\mathrm{MoS}_{2}$ /graphene superlattice for efficient sodium storage and hydrogen evolution. ACS Energy Lett. 3, 997-1005 (2018).

34. Liu, M. et al. 3D conductive network supported monolithic molybdenum disulfide nanosheets for high-performance lithium storage applications. Adv. Mater. Interfaces 4, 1601228 (2017).

35. Zhang, P. et al. High areal capacitance for lithium ion storage achieved by a hierarchical carbon/mos2 aerogel with vertically aligned pores. ACS Appl. Energy Mater. 1, 4814-4823 (2018). 
36. Bai, Y.-L., Liu, Y.-S., Ma, C., Wang, K.-X. \& Chen, J.-S. Neuron-inspired design of high-performance electrode materials for sodium-ion batteries. ACS Nano 12, 11503-11510 (2018).

37. David, L., Bhandavat, R. \& Singh, G. $\mathrm{MoS}_{2}$ /graphene composite paper for sodium-ion battery electrodes. ACS Nano 8, 1759-1770 (2014).

38. Pan, Q. et al. Construction of $\mathrm{MoS}_{2} / \mathrm{C}$ hierarchical tubular heterostructures for high-performance sodium ion batteries. ACS Nano 12, 12578-12586 (2018).

39. Liu, M. et al. A highly conductive carbon-sulfur film with interconnected mesopores as an advanced cathode for lithium-sulfur batteries. Chem. Commun. 53, 9097-9100 (2017).

40. Liu, M. et al. A hybrid carbon aerogel with both aligned and interconnected pores as interlayer for high-performance lithium-sulfur batteries. Nano Res. 9, 3735-3746 (2016).

41. Chang, J., Sheng, L., Wei, T. \& Fan, Z. Molecular diffusion-driven motion in 2D graphene film. Adv. Funct. Mater. 28, 1707053 (2018).

42. Sun, H. et al. Novel graphene/carbon nanotube composite fibers for efficient wire-shaped miniature energy devices. Adv. Mater. 26, 2868-2873 (2014).

43. Xiao, H., Xie, P., Qiu, S. J., Rong, M. Z. \& Zhang, M. Q. Ultrathin-graphite foam with high mechanical resilience and electroconductibility fabricated through morphology-controlled solid-state pyrolysis of polyaniline foam. Carbon N. Y. 139, 648-655 (2018).

44. Gao, H.-L. et al. Super-elastic and fatigue resistant carbon material with lamellar multi-arch microstructure. Nat. Commun. 7, 12920 (2016)

45. Zhang, $\mathrm{H}$. et al. Aligned two- and three-dimensional structures by directional freezing of polymers and nanoparticles. Nat. Mater. 4, 787 (2005).

46. Cui, C. et al. Three-dimensional carbon frameworks enabling $\mathrm{MoS}_{2}$ as anode for dual ion batteries with superior sodium storage properties. Energ. Storage Mater. 15, 22-30 (2018).

47. Wang, G. et al. Vertically aligned $\mathrm{MoS}_{2}$ nanosheets patterned on electrochemically exfoliated graphene for high-performance lithium and sodium storage. Adv. Energy Mater. 8, 1702254 (2017).

48. Su, D., Dou, S. \& Wang, G. Ultrathin $\mathrm{MoS}_{2}$ nanosheets as anode materials for sodium-ion batteries with superior performance. Adv. Energy Mater. 5, 1401205 (2014).

49. Liu, Y. et al. Liquid phase exfoliated $\mathrm{MoS}_{2}$ nanosheets percolated with carbon nanotubes for high volumetric/areal capacity sodium-ion batteries. ACS Nano 10, 8821-8828 (2016).

50. Sun, D. et al. $\mathrm{MoS}_{2}$ /graphene nanosheets from commercial bulky $\mathrm{MoS}_{2}$ and graphite as anode materials for high rate sodium-ion. Batter. Adv. Energy Mater. 8, 1702383 (2017).

51. $\mathrm{Hu}, \mathrm{Z}$. et al. $\mathrm{MoS}_{2}$ nanoflowers with expanded interlayers as high-performance anodes for sodium-ion batteries. Angew. Chem. Int. Ed. 53, 12794-12798 (2014).

52. Wang, Y.-X., Chou, S.-L., Wexler, D., Liu, H.-K. \& Dou, S.-X. Highperformance sodium-ion batteries and sodium-ion pseudocapacitors based on $\mathrm{MoS}_{2}$ /graphene. Compos. Chem. Eur. J. 20, 9607-9612 (2014).

53. Choi, S. H., Ko, Y. N., Lee, J.-K. \& Kang, Y. C. 3D $\mathrm{MoS}_{2}$-graphene microspheres consisting of multiple nanospheres with superior sodium ion storage properties. Adv. Funct. Mater. 25, 1780-1788 (2015).

54. Hu, Z., Liu, Q., Chou, S.-L. \& Dou, S.-X. Advances and challenges in metal sulfides/selenides for next-generation rechargeable sodium-ion batteries. $A d v$. Mater. 29, 1700606 (2017).

55. Xu, X. et al. Controllable design of $\mathrm{MoS}_{2}$ nanosheets anchored on nitrogendoped graphene: toward fast sodium storage by tunable pseudocapacitance. Adv. Mater. 30, 1800658 (2018).
56. Yao, K. et al. Synthesis of grain-like $\mathrm{MoS}_{2}$ for high-performance sodium-ion batteries. ChemSusChem 11, 2130-2137 (2018).

57. Xie, X. et al. $\mathrm{MoS}_{2}$ nanosheets vertically aligned on carbon paper: a freestanding electrode for highly reversible sodium-ion. Batter. Adv. Energy Mater. 6, 1502161 (2015).

58. Li, P., Jeong, J. Y., Jin, B., Zhang, K. \& Park, J. H. Vertically oriented $\mathrm{MoS}_{2}$ with spatially controlled geometry on nitrogenous graphene sheets for highperformance sodium-ion batteries. Adv. Energy Mater. 8, 1703300 (2018).

\section{Acknowledgements}

This work was financially supported by the National Natural Science Foundation of China (51703087, 51433001,51572116 and 51871113), and the Natural Science Foundation of Jiangsu Province (BK20150238, BK20170240).

\section{Author contributions}

M.L., Y.Y., C.L., T.L. and S.Z. proposed and supervised the project. M.L., Y.Y. and P.Z conceived and performed the experiments. M.L. and P.Z. synthesized the CNFIG materials. Z.Q. did the SEM measurements. Y.Y. and P.Z. fabricated the batteries and carried out the electrochemical performance tests. M.L., Y.Y., C.L., T.L. and S.Z. wrote the paper. All the authors contributed to the results analyses, discussions, and have approved the final version of the paper.

\section{Additional information}

Supplementary Information accompanies this paper at https://doi.org/10.1038/s41467019-11925-z.

Competing interests: The authors declare no competing interests.

Reprints and permission information is available online at http://npg.nature.com/ reprintsandpermissions/

Peer review information: Nature Communications thanks Chenghao Yang and other anonymous reviewer(s) for their contribution to the peer review of this work. Peer reviewer reports are available.

Publisher's note: Springer Nature remains neutral with regard to jurisdictional claims in published maps and institutional affiliations.

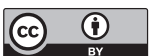

Open Access This article is licensed under a Creative Commons Attribution 4.0 International License, which permits use, sharing adaptation, distribution and reproduction in any medium or format, as long as you give appropriate credit to the original author(s) and the source, provide a link to the Creative Commons license, and indicate if changes were made. The images or other third party material in this article are included in the article's Creative Commons license, unless indicated otherwise in a credit line to the material. If material is not included in the article's Creative Commons license and your intended use is not permitted by statutory regulation or exceeds the permitted use, you will need to obtain permission directly from the copyright holder. To view a copy of this license, visit http://creativecommons.org/ licenses/by/4.0/.

(c) Crown 2019 